\begin{tabular}{|c|c|}
\hline Title & Excitation temperature of a solution plasma during nanoparticle synthesis \\
\hline Author(s) & Saito, Genki; Nakasugi, Y uki; A kiyama, Tomohiro \\
\hline Citation & $\begin{array}{l}\text { Journal of A pplied Physics, 116(8), } 83301 \\
\text { https://doi.org/10.1063/1.4894156 }\end{array}$ \\
\hline Issue Date & $201408-28$ \\
\hline Doc URL & http:/hdl.handle.net/2115/57533 \\
\hline Rights & $\begin{array}{l}\text { Copyright } 2014 \text { A merican Institute of Physics. This article may be downloaded for personal use only. A ny other use } \\
\text { requires prior permission of the author and the A merican Institute of Physics. The following article appeared in Journal } \\
\text { of A pplied Physics } \\
\text { 116, } 083301 \text { (2014) and may be found at http://dx.doi.org/10.1063/1.4894156 }\end{array}$ \\
\hline Tyре & article \\
\hline File Information & 1.4894156.pdf \\
\hline
\end{tabular}

Instructions for use 


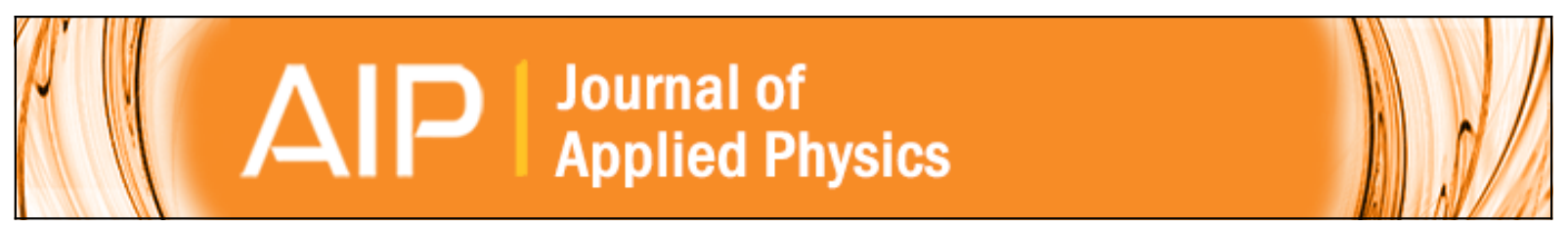

\section{Excitation temperature of a solution plasma during nanoparticle synthesis}

Genki Saito, Yuki Nakasugi, and Tomohiro Akiyama

Citation: Journal of Applied Physics 116, 083301 (2014); doi: 10.1063/1.4894156

View online: http://dx.doi.org/10.1063/1.4894156

View Table of Contents: http://scitation.aip.org/content/aip/journal/jap/116/8?ver=pdfcov

Published by the AIP Publishing

\section{Articles you may be interested in}

High-speed camera observation of solution plasma during nanoparticles formation

Appl. Phys. Lett. 104, 083104 (2014); 10.1063/1.4865498

Dissolving, trapping and detrapping mechanisms of hydrogen in bcc and fcc transition metals

AIP Advances 3, 012118 (2013); 10.1063/1.4789547

Electron back-scattering coefficient below $5 \mathrm{keV}$ : Analytical expressions and surface-barrier effects J. Appl. Phys. 112, 084905 (2012); 10.1063/1.4759367

Optical Constants and Inelastic Electron-Scattering Data for 17 Elemental Metals

J. Phys. Chem. Ref. Data 38, 1013 (2009); 10.1063/1.3243762

Effect of $3 \mathrm{~d}, 4 \mathrm{~d}$, and $5 \mathrm{~d}$ transition metal doping on damping in permalloy thin films J. Appl. Phys. 101, 033911 (2007); 10.1063/1.2436471

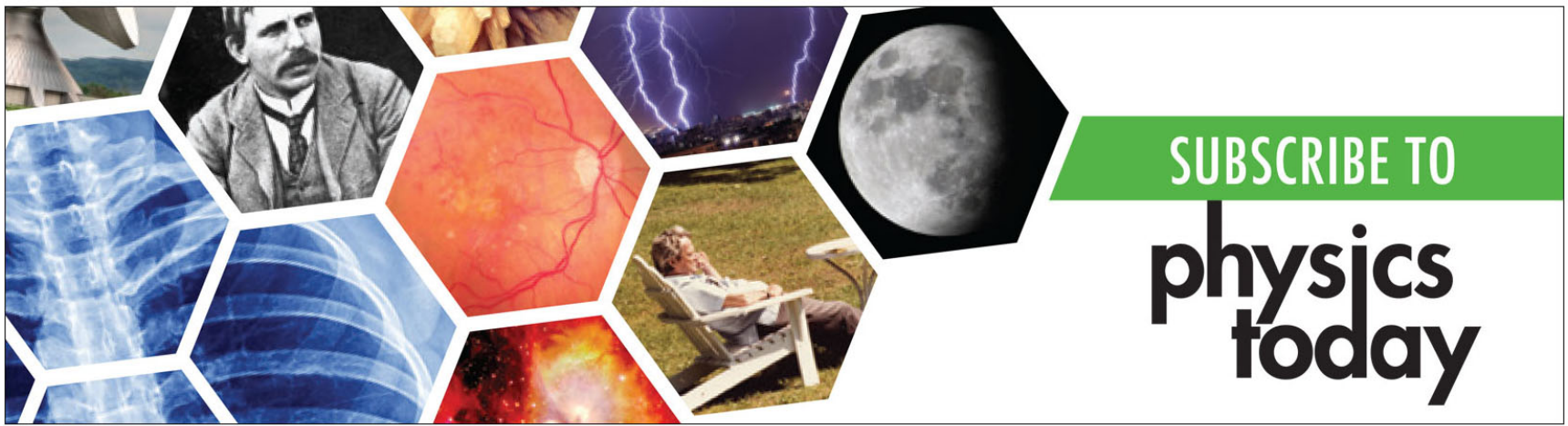




\title{
Excitation temperature of a solution plasma during nanoparticle synthesis
}

\author{
Genki Saito, ${ }^{\text {a) }}$ Yuki Nakasugi, and Tomohiro Akiyama \\ Center for Advanced Research of Energy and Materials, Hokkaido University, Sapporo 060-8628, Japan
}

(Received 22 May 2014; accepted 17 August 2014; published online 27 August 2014)

\begin{abstract}
Excitation temperature of a solution plasma was investigated by spectroscopic measurements to control the nanoparticle synthesis. In the experiments, the effects of edge shielding, applied voltage, and electrode material on the plasma were investigated. When the edge of the Ni electrode wire was shielded by a quartz glass tube, the plasma was uniformly generated together with metallic Ni nanoparticles. The emission spectrum of this electrode contained $\mathrm{OH}, \mathrm{H}_{\alpha}, \mathrm{H}_{\beta}, \mathrm{Na}, \mathrm{O}$, and $\mathrm{Ni}$ lines. Without an edge-shielded electrode, the continuous infrared radiation emitted at the edge created a high temperature on the electrode surface, producing oxidized coarse particles as a result. The excitation temperature was estimated from the Boltzmann plot. When the voltages were varied at the edge-shielded electrode with low average surface temperature by using different electrolyte concentrations, the excitation temperature of current-concentration spots increased with an increase in the voltage. The size of the Ni nanoparticles decreased at high excitation temperatures. Although the formation of nanoparticles via melting and solidification of the electrode surface has been considered in the past, vaporization of the electrode surface could occur at a high excitation temperature to produce small particles. Moreover, we studied the effects of electrodes of Ti, Fe, Ni, Cu, Zn, Zr, Nb, Mo, Pd, Ag, W, Pt, Au, and various alloys of stainless steel and $\mathrm{Cu}-\mathrm{Ni}$ alloys. With the exception of $\mathrm{Ti}$, the excitation temperatures ranged from 3500 to $5500 \mathrm{~K}$ and the particle size depended on both the excitation temperature and electrode-material properties. C 2014 AIP Publishing LLC. [http://dx.doi.org/10.1063/1.4894156]
\end{abstract}

\section{INTRODUCTION}

Plasma generation in a liquid is currently being investigated for application in a variety of fields such as nanoparticle synthesis, ${ }^{1,2}$ hydrogen production, ${ }^{3}$ surface modification, ${ }^{4}$ polymerization, ${ }^{5}$ and the decomposition of harmful dissolved substances. ${ }^{6-9}$ To establish the technologies for plasma in liquid, plasma diagnosis has become much more important. Many methods for plasma diagnosis, such as electrical measurement, optical emission spectroscopy (OES) containing the broadening of a spectral line, Langmuir probes, and laser irradiation have been proposed in a past. ${ }^{10}$ Among the various methods, OES is one of the most used diagnostic method for a liquid plasma. ${ }^{11}$ The analysis of a light emission spectrum from a plasma has revealed the excitation temperature, current density, and active radicals that constitute the plasma.

When a direct-current (DC) voltage is applied to a conductive electrode in a solution, a plasma layer is generated at the interface between the electrode and the solution. The formation of the plasma is due to the heating of the solution near the electrode. An electrode under such conditions was named "a glow discharge electrode" by Hickling and Ingram. ${ }^{12}$ They performed the conventional electrolysis of water and increased the current by increasing the voltage from a low value. Because heating of the solution due to electrical resistance was concentrated at the electrode/solution interface, the solution near the cathode was heated to its boiling point, and a vapor layer was generated. If the voltage was sufficiently high, the vapor layer formed a discharge

a)E-mail: genki@eng.hokudai.ac.jp plasma that was accompanied by light emission. ${ }^{13}$ The emission spectra of this radiation depended on the constituent elements of the electrolyte and electrode materials. ${ }^{14,15}$

Recently, a solution plasma has been applied to the synthesis of nanoparticles. The produced particle size and compositions were affected by the plasma conditions, such as the electrode shape, ${ }^{16,17}$ voltage,${ }^{18,19}$ atmospheric pressure, ${ }^{20}$ and material. ${ }^{21}$ Previous reports indicated that the shape of the electrode affects the plasma conditions and obtained nanoparticles. When the electrode has an edge similar to the tip of a wire, the transition from a partial-plasma region to a full-plasma region occurred with the strong emission of light. ${ }^{16}$ This transition is caused by the current concentration at the edge induced by a highly inhomogeneous electric field. The products are oxidized and agglomerate after the transition. When the electrode is symmetric and flat without edges, metallic particles were mainly synthesized. For controlling the particle size, higher voltages using low electrolyte concentrations were effective. The particle size decreased from $137 \mathrm{~nm}$ to $70 \mathrm{~nm}$ when the applied voltage changed from $65 \mathrm{~V}$ to $590 \mathrm{~V} .^{22}$ As mentioned above, the experimental parameters for controlling the synthesized nanoparticles has been investigated. However, the relationship between the properties of the plasma, such as the excitation temperatures and synthesized nanoparticles, has not been clearly understood. Additionally, formation mechanism of nanoparticles is still unclear.

In this study, spectroscopic measurements of a solution plasma using DC were performed during nanoparticle synthesis to control the product size and investigate the particles formation. In the experiments, the effects of edge-shielding, 
applied voltage, and electrode material on the plasma were mainly studied. The excitation temperature was estimated from the emission spectrum by applying the Boltzmann plot method with the assumption of local thermodynamic equilibrium (LTE). Furthermore, observations by a high-speed camera were carried out to investigate the plasma generation.

\section{EXPERIMENTS}

As reported previously, ${ }^{16,19,22,23}$ the experimental setup consisted of two electrodes in a glass cell with a capacity of $300 \mathrm{ml}$. The cathode consisted of a metal wire with a diameter of $1.0 \mathrm{~mm}$. When the edge shielding and electrolyte concentration were investigated, a $\mathrm{Ni}$ wire was used as a cathode. When the effects of the electrode material were investigated, the cathode materials were wires comprised of Ti, Fe, Ni, Cu, Zn, Zr, Nb, Mo, Pd, Ag, W, Pt, Au, and various alloys of stainless steel and $\mathrm{Cu}-\mathrm{Ni}$ alloys. The upper and lower parts of the cathode were shielded by a quartz glass tube to maintain the exposed length at $10 \mathrm{~mm}$. The exposed portion functioned as the actual electrode. For no edge shielding, the lower shield was removed. The anode consisted of a Pt wire with a length of $1000 \mathrm{~mm}$ and a diameter of $0.5 \mathrm{~mm}$, and it was bent into a semicircular mesh. The distance between the electrodes was maintained at $30 \mathrm{~mm}$. A $0.1 \mathrm{M} \mathrm{NaOH}$ solution was used as the standard electrolyte. The concentrations of the $\mathrm{NaOH}$ solutions varied from 0.001 to $5.0 \mathrm{M}$ for changing the applied voltages. The conductivity
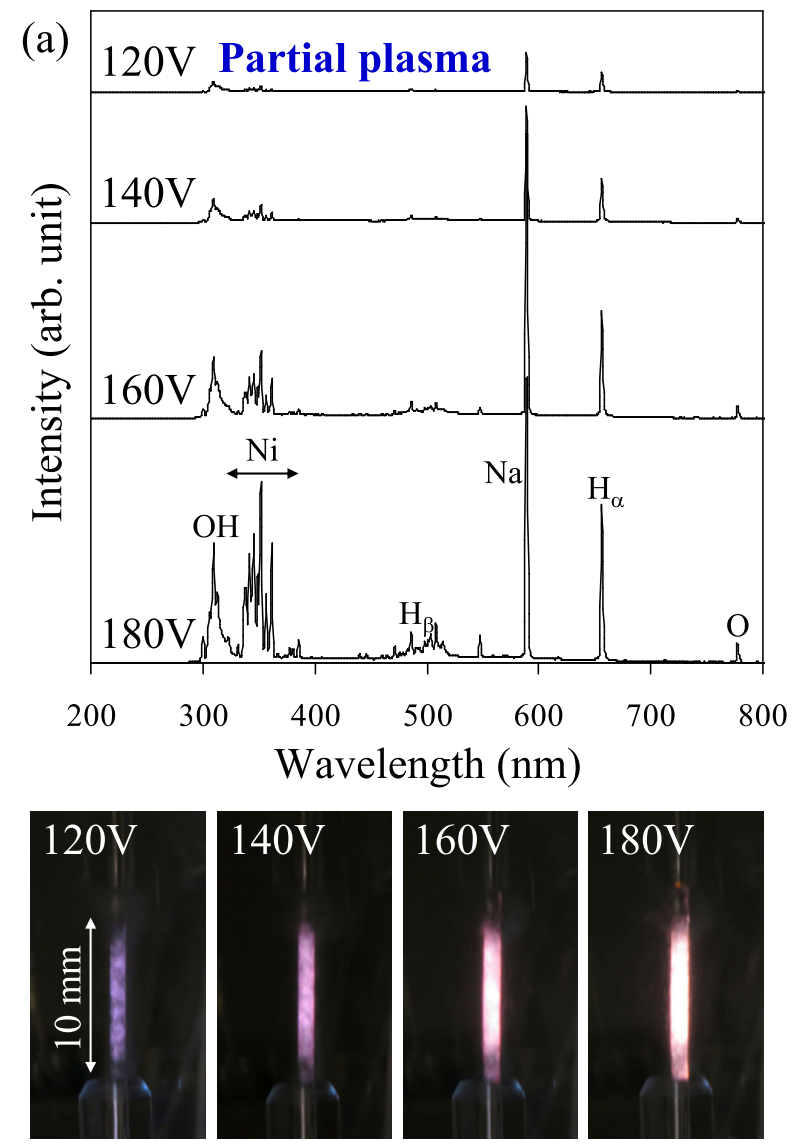

of the solution affects to the voltage for plasma generation. The solution temperature was recorded every $5 \mathrm{~s}$ at a depth of $10 \mathrm{~mm}$ using a polymer-coated thermistor thermometer (Ondotori TR-71Ui, T\&D). The current and voltage were recorded every $2 \mathrm{~s}$ using a DC power supply $(\mathrm{ZX}-800 \mathrm{H}$, Takasago). Light emission from the plasma was measured using a visible-light spectrophotometer (USB 2000+, Ocean Optics) with an observation range from 200 to $850 \mathrm{~nm}$. A high-speed camera (FASTCAM SA5, 1/20000 s) was used to reveal the plasma conditions. After electrolysis, the products were collected by centrifugation and washed with deionized water. Subsequently, the products and post-experiment cathode wires were observed using a JSM-7001F (JEOL) fieldemission scanning electron microscope (SEM).

\section{RESULTS AND DISCUSSION}

\section{A. Effects of edge shielding on the Ni electrode}

We investigated the spectra of light emission from an edge-shielded Ni electrode and a non-edge-shielded Ni electrode. For both electrodes, a glow discharge with light emission occurred at approximately $120 \mathrm{~V}$. The intensity of light emission increased with increasing voltage, which means that the net area of the discharge increased with increasing voltage. The discharge in this range is referred to as the partial-plasma region. Figure 1(a) shows the spectra of the plasma and photographs of the Ni electrode. As reported in other works, ${ }^{9,14,15}$ strong emissions of $\mathrm{H}_{\alpha}(656 \mathrm{~nm})$ and $\mathrm{H}_{\beta}$
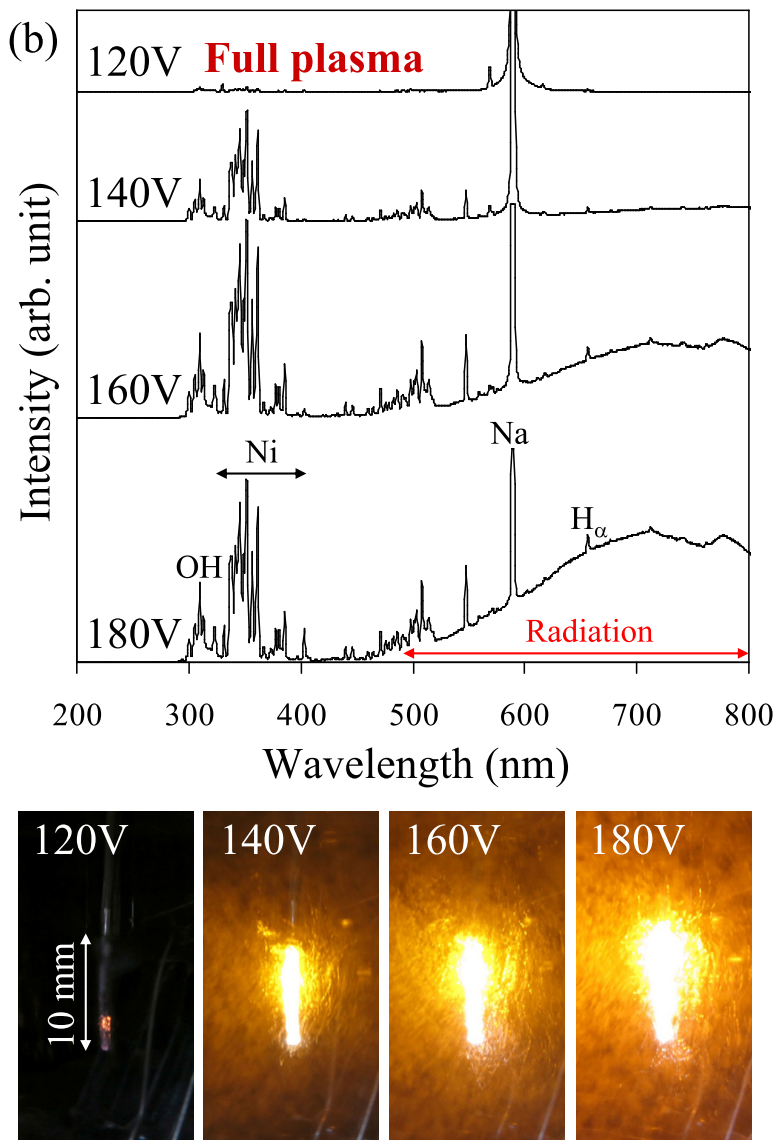

FIG. 1. Spectra from the Ni electrode and the corresponding photographs during light emission: (a) partial-plasma conditions, in which the edge of the electrode was shielded by a quartz glass tube and (b) full-plasma conditions with light emission. 

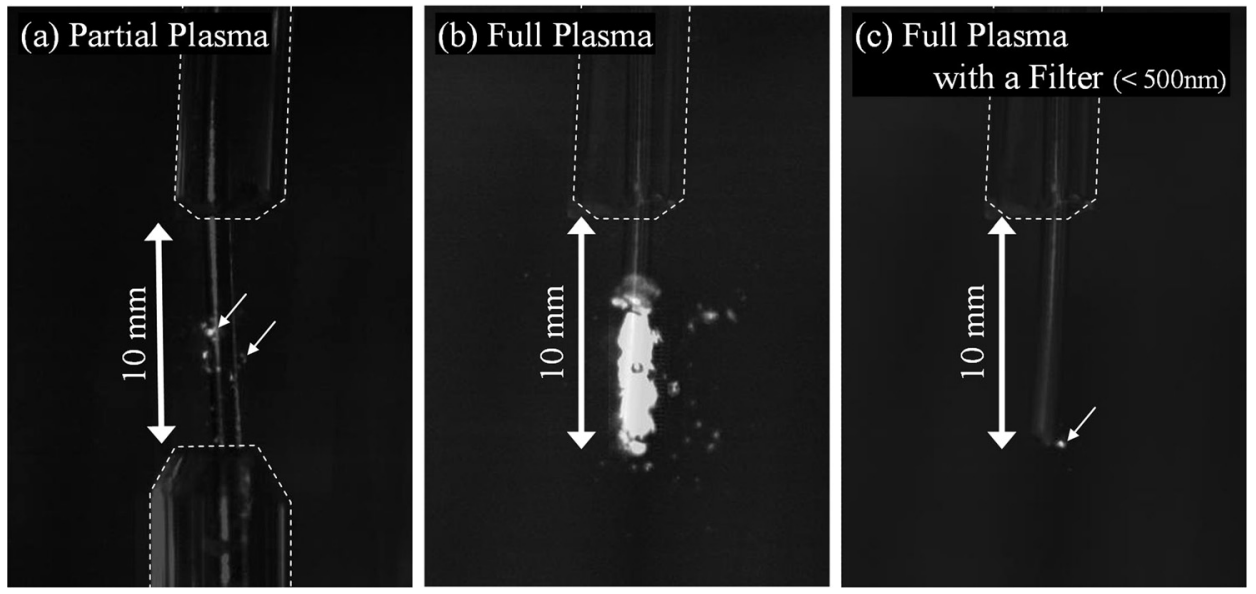

FIG. 2. Photographs of the Ni electrode taken by a high-speed camera, where plasma emission was observed at an exposed portion. The frame rate was $1 / 20000$ s. For partial-plasma conditions (a), the light-emission spots moved quickly. When the full-plasma electrode was used, infrared radiation radiated continuously at the electrode edge (b), and plasma emission was also centered on the edge (c) (Multimedia view) [URL: http:// dx.doi.org/10.1063/1.4894156.1].

$(486 \mathrm{~nm})$ as the Balmer atomic hydrogen lines, the $\mathrm{OH} \mathrm{A}$ ${ }^{2} \Sigma^{+}-\mathrm{X}^{2} \Pi(0,0)$ band $(309 \mathrm{~nm})$, and $\mathrm{O}(777 \mathrm{~nm})$ were detected. The strong emission of $\mathrm{Na}(589 \mathrm{~nm})$ was derived from the $\mathrm{NaOH}$ electrolyte solution. The emissions from the $\mathrm{Ni}$ electrode $(341,357,362$, and $386 \mathrm{~nm})$ increased at a higher voltage because of the increase in the electrode temperature. The average temperature of the entire Ni electrode surface is believed to be low in this partial-plasma region. Without edge shielding, the transition from a partial plasma to a full plasma occurred at approximately $173 \mathrm{~V}$. After the transition, the current increased from 0.37 to $0.51 \mathrm{~A}$. The emission spectra at $180 \mathrm{~V}$ under full-plasma conditions exhibited strong infrared radiation, which suggests that the entire Ni electrode surface was strongly heated owing to the high input power induced by the higher current flow.

Figure 2 shows photographs of the Ni electrode taken by a high-speed camera at a frame rate of $1 / 20000 \mathrm{~s}$. In the partial-plasma region, the entire area of the plasma was small, and the light-emitting points moved quickly, as shown in Fig. 2(a). Under such conditions, the surface temperature of the entire electrode was low, and small metallic nanoparticles with dimensions below $300 \mathrm{~nm}$ were produced. ${ }^{16}$ In contrast, the full-plasma electrode continuously emitted infrared radiation, as shown in Fig. 2(b); coarse and oxidized particles measuring over $700 \mathrm{~nm}$ in diameter were produced because of the higher electrode temperature, which enabled melted particles to easily agglomerate on the electrode surface to form coarse particles.

Photographs without infrared radiation were taken by using a cut filter, and the emission spots of the plasma were also observed at the edge of the electrode in Fig. 2(c). The electrode surface after electrolysis was characterized by an SEM. ${ }^{16}$ Particles were uniformly attached to the electrode surface of the partial plasma. In contrast, the full-plasma electrode had many cracks that were most likely caused by the thermal expansion of the electrode at high temperature. The coarse particles were produced from the rough surface of the electrode. From these results, it is found that an electrode having a uniform and symmetric shape maintains a partial plasma effectively that produces small metallic nanoparticles.

\section{B. Effects of the electrolyte concentration}

As reported by many researchers, ${ }^{19,24}$ the electrical conductivity of the solution affects the plasma formation and nanoparticle synthesis. When the concentration of the electrolysis solution is low, the current decreases, and the plasma generation requires a high voltage owing to an increase in the solution resistance. Figure 3(a) shows the reported data of the relationship between the applied voltage and the mean diameter produced by a solution plasma in the partial

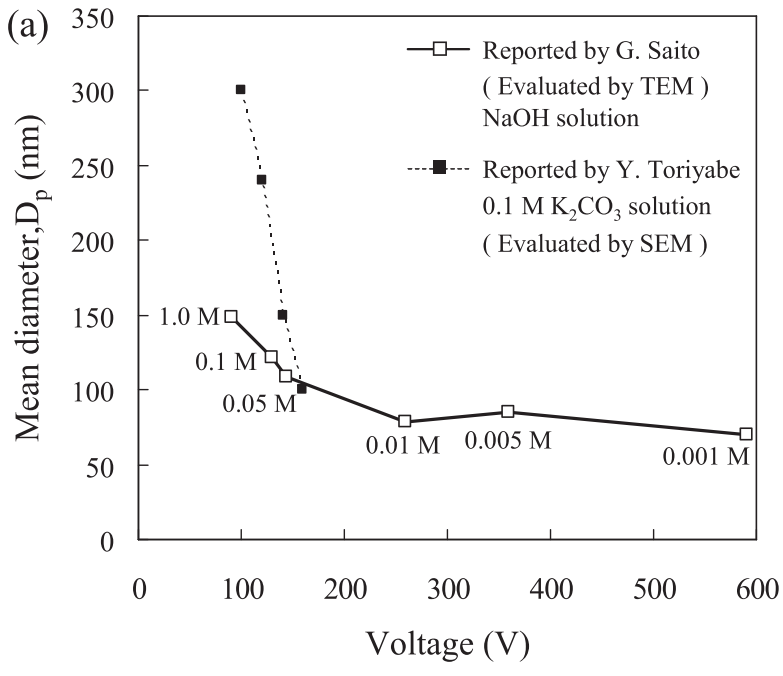

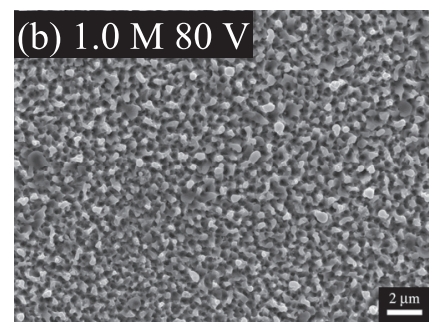

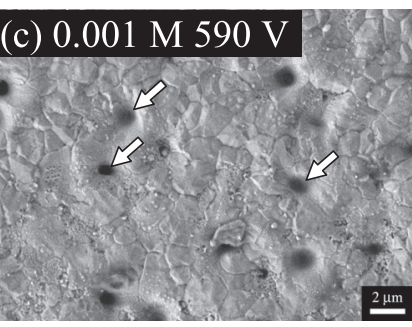

FIG. 3. (a) Reported data of the relationships between the applied voltage and the mean diameters of Ni particles produced by a solution plasma. The particle size decreased with an increase in the applied voltages. (b), (c) SEM images of the Ni electrode after electrolysis at different voltages. 


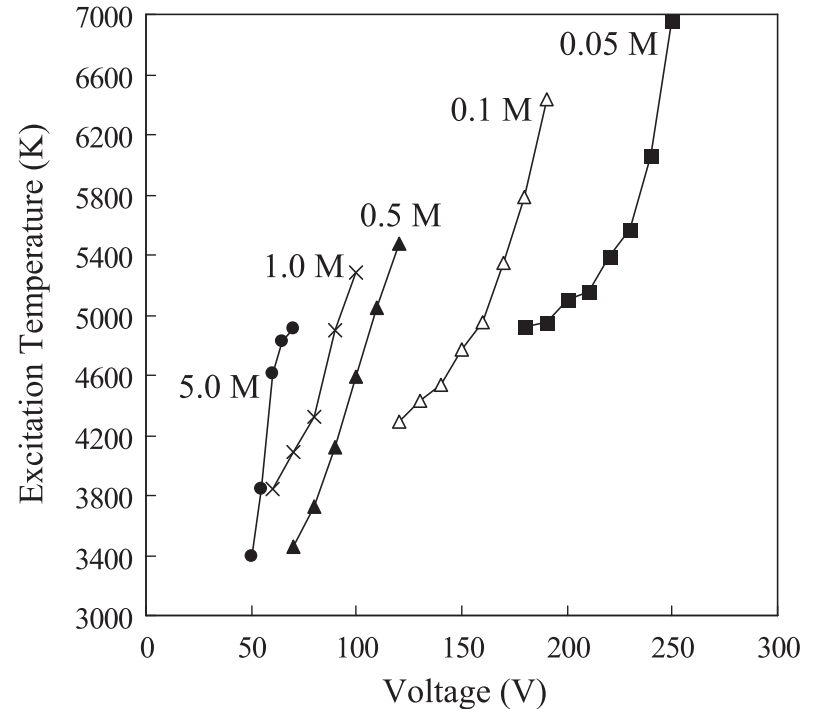

FIG. 4. Excitation temperature versus the applied voltage at different concentrations of the electrolyte, in which a $\mathrm{Ni}$ wire was used as a cathode. The electron temperatures were calculated by the intensity of the light spectrum of $\mathrm{H}_{\alpha}(656.3 \mathrm{~nm})$ and $\mathrm{H}_{\beta}(486.1 \mathrm{~nm})$ when the electrons are assumed to have a Boltzmann distribution.

plasma. ${ }^{18,19,22}$ The particle size tends to decrease with an increase in the applied voltage. Additionally, the SEM observation of the electrode after electrolysis at different voltages, shown in Figs. 3(b) and 3(c), indicates that a higher applied voltage with a low concentration forms holes on the electrode surface. The formation mechanism of these holes is still unclear.

To examine the effects of the electrolyte concentration and voltage, the excitation temperature was calculated from the Boltzmann plot by assuming LTE as ${ }^{21,25,26}$

$$
\ln \left(\frac{I_{i j} \lambda_{i j}}{g_{i} A_{i j}}\right)=-\frac{E_{i}}{k T}+\ln \left(\frac{N(T)}{U(T)}\right),
$$

where $I_{i j}$ is the emission intensity of $\mathrm{H}_{\alpha}(656 \mathrm{~nm})$ and $\mathrm{H}_{\beta}$ (486 nm), $\lambda_{i j}$ is the wavelength, $g_{i}$ is the statistical weight of the upper level, $A_{i j}$ is the transition probability, $E_{i}$ is the upper level energy, $k$ is the Boltzmann constant, $N(T)$ is the total number density of neutrals, and $U(T)$ is the partition function. There is a possibility that the LTE model is not applicable to this plasma. In addition, we should have considered the effects of light absorption of the solution. Therefore, the absolute value of the calculated excitation temperature might not be an exact value. However, we can relatively compare the plasma conditions by using the excitation temperature. The excitation temperatures obtained at different voltages are summarized in Fig. 4, which reveals increases with increasing applied voltage. The high accelerated voltage excited the plasma. Below a concentration of $0.01 \mathrm{M}$, the intensity of light emission was too small for calculation of the excitation temperature. At $140 \mathrm{~V}$ and a concentration of $0.1 \mathrm{M}$, the excitation temperature was $4500 \mathrm{~K}$. Overall, the temperatures ranged from 3400 to $7000 \mathrm{~K}$ under various conditions. Table I summarizes the excitation temperatures from various plasmas in a liquid, which were influenced by the plasma source, solution, applied voltage, electric power, and pressure. Hattori et al. reported that the excitation temperature ranged from approximately 3000 to $5000 \mathrm{~K}$ for a microwave plasma and a high-frequency plasma in a liquid. ${ }^{21}$ In the case of pulsed nanosecond laser ablation reported by Mortazavi et al., the excitation temperature range was $4900-7300 \mathrm{~K} .^{26}$ Some researchers have reported a temperature over $10000 \mathrm{~K} .^{27,28}$ Under such conditions, the formation of nanoparticles via melting and solidification of the electrode surface was considered. Furthermore, vaporization of an electrode can occur when the excitation temperature exceeds the boiling temperature of the electrode material. This was probably the cause of holes generated on the electrode surface at a high applied voltage, shown in Fig. 3(c). In the partial-plasma region, the average temperature of the electrode surface was low. However, the excitation temperature of the plasma generated at current concentration spots, as shown in Fig. 2(a), increased at high applied voltage, forming a metal vapor that produced small particles. The formation mechanism at various plasma conditions was summarized in Fig. 5.

TABLE I. Excitation temperatures from various plasmas in a liquid.

\begin{tabular}{|c|c|c|c|c|}
\hline Plasma source & Liquid & Temperature $(\mathrm{K})$ & Emission & Reference \\
\hline Microwave plasma in water & Pure water & $\begin{array}{l}4000 \pm 500 \mathrm{~K} \\
3200 \pm 500 \mathrm{~K} \\
3300 \pm 100 \mathrm{~K}\end{array}$ & $\begin{array}{c}\mathrm{Mg} \\
\mathrm{Zn} \\
\mathrm{H}\end{array}$ & 21 \\
\hline RF plasma & $\mathrm{NaCl}$ solution & $4500 \mathrm{~K}$ & $\mathrm{H}$ & 24 \\
\hline RF plasma & Pure water & $\begin{array}{l}3300-4800 \mathrm{~K} \\
1500-3700 \mathrm{~K}\end{array}$ & $\begin{array}{c}\mathrm{H} \\
\mathrm{OH}\end{array}$ & 29 \\
\hline Pulsed discharge (DC) & $\mathrm{NH}_{4} \mathrm{NO}_{3}+\mathrm{Fe}\left(\mathrm{NO}_{3}\right)_{3}$ & $\begin{array}{l}13000 \mathrm{~K} \\
15000 \mathrm{~K}\end{array}$ & $\begin{array}{l}\mathrm{Fe} \\
\mathrm{Fe}\end{array}$ & 27 \\
\hline 27.12 MHz in liquid plasma & Water & $\begin{array}{l}3200-3700 \mathrm{~K} \\
3500-5000 \mathrm{~K}\end{array}$ & $\begin{array}{c}\mathrm{H} \\
\mathrm{OH}\end{array}$ & 20 \\
\hline RF plasma & Pure water & $3500 \mathrm{~K}$ & $\mathrm{OH}$ & 9 \\
\hline RF plasma & $\mathrm{NaCl}$ solution & $20000 \mathrm{~K}$ & $\mathrm{Fe}$ & 28 \\
\hline HF plasma, $27.12 \mathrm{MHz}$ & Water & $4500 \pm 300 \mathrm{~K}$ & $\mathrm{H}$ & 30 \\
\hline Microwave plasma, $2.45 \mathrm{GHz}$ & & $3000-4000 \mathrm{~K}$ & $\mathrm{H}$ & \\
\hline Laser ablation & DI water & $4900-7300 \mathrm{~K}$ & $\mathrm{Pd}$ & 26 \\
\hline DC-excited discharge & Water or $\mathrm{KCl}$ solution & $2500-3000 \mathrm{~K}$ & $\mathrm{OH}$ & 25 \\
\hline
\end{tabular}


(a) Melting in full plasma

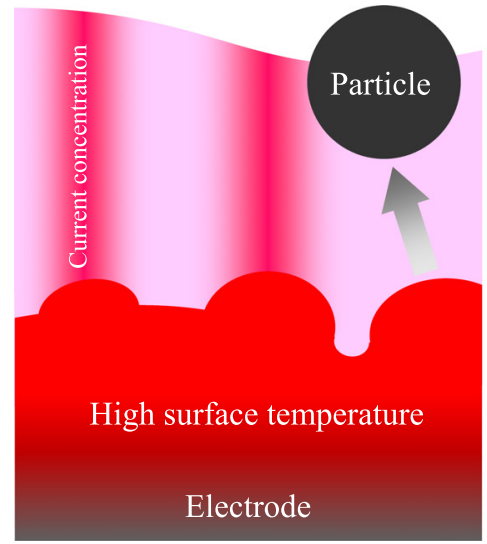

(b) Melting in partial plasma

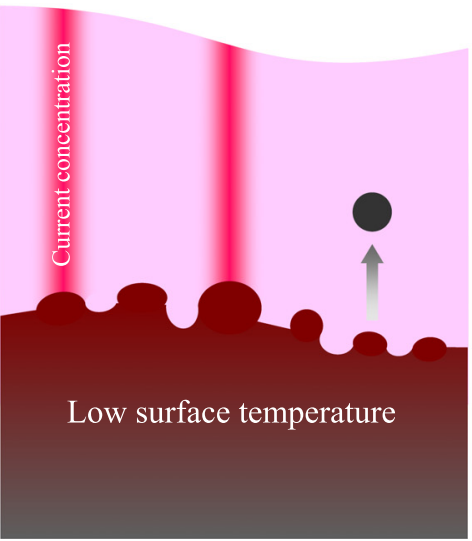

(c) Vaporizing in partial plasma with high excitation temperature.

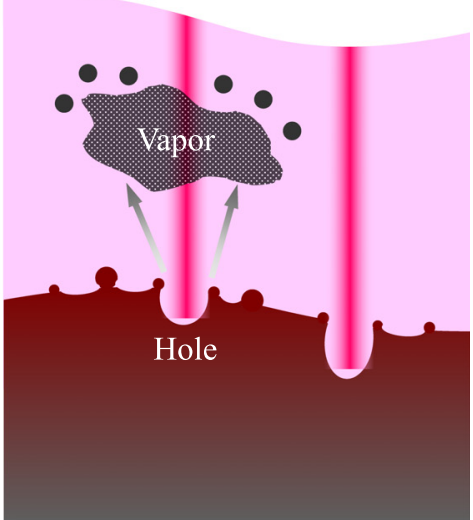

FIG. 5. Particles formation at various plasma conditions. (a) melting of the electrode surface in full plasma, in which the surface temperature of the electrode is high. (b) melting in partial plasma with low surface temperature of the electrode. (c) vaporizing of the electrode with high excitation temperature of the plasma.

The excitation temperature was changed by not only the applied voltage but also the electrolyte concentration. When the concentration was decreased, a higher voltage was required for plasma generation; therefore, the excitation temperature was increased at lower electrolyte concentration. Typical I-V curves at different concentrations (Fig. 6) show that the current during plasma generation was lower at lower electrolyte concentrations. The inset curve explains what occurred in each region. At low voltage, electrolysis of water took place, and the current increased with voltage in accordance with Ohm's law (Region 1). Because the thermal loss was concentrated at the cathode-solution interface, the solution near the cathode was heated to the boiling point and a steam-containing gas layer was generated. Once the gas layer

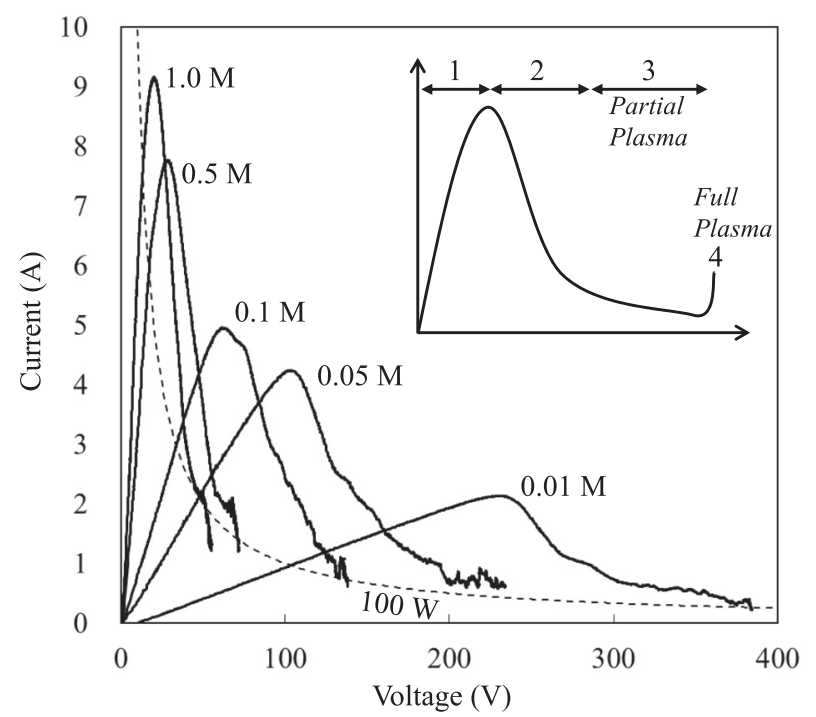

FIG. 6. Typical $I$ - $V$ curves at different concentrations of the electrolyte solution. The inset curve explains what occurred in each region. Region 1: at low voltage, electrolysis of water took place. Region 2: when the solution temperature of the surrounding electrode was increased to the boiling point, a gas layer was generated on the electrode surface, which prevented the current from flowing. Region 3: the gas layer grew to the partial-plasma region. Point 4: at high applied voltage, the partial plasma became a full plasma. The dashed line corresponds to a power of $100 \mathrm{~W}$. was formed on the cathode surface, the current could not increase any further, and it decreased (Region 2) because the cathode electrode and the solution were no longer in contact (breakdown). If the voltage was sufficiently high, a discharge with intense light emission would have begun in the gas layer (Region 3). At high applied voltage, the transition from a partial plasma to full plasma (Point 4) occurred. When the applied voltage was the same at different concentrations, the excitation temperature changed: (concentration, voltage, and excitation temperature $)=(0.05 \mathrm{M}, 180 \mathrm{~V}, 4900 \mathrm{~K})$, and $(0.1 \mathrm{M}, 180 \mathrm{~V}, 5800 \mathrm{~K})$. These phenomena are explained by the difference in region at $I-V$ curve (Fig. 6). The $0.05 \mathrm{M}$ $180 \mathrm{~V}$ condition corresponds to region 2 in Fig. 6, which is the transition area from gas layer to plasma. In contrast, the $0.1 \mathrm{M}-180 \mathrm{~V}$ is region 3 in close to region 4 . Compared to plasma at region 3 , the excitation temperature of region 2 tends to be low due to low emission intensity of plasma as shown in Fig. 1. Even though the applied voltage is same, the excitation temperature is changed when the plasma condition is different. From these results, it was found that the high applied voltage in the partial-plasma region were effective for synthesizing small nanoparticles owing to the high excitation temperature.

\section{Effects of the electrode material}

In Secs. III A and III B, we focused on a Ni electrode. Here, the effects of the electrode material are presented under the same operating conditions of a $0.1 \mathrm{M} \mathrm{NaOH}$ electrolyte solution at $140 \mathrm{~V}$ for an edge-shielded electrode. Figure 7 shows the spectrum of light emission from each electrode material. Similar to the Ni electrode in Fig. 1, emissions from $\mathrm{OH}, \mathrm{H}_{\alpha}, \mathrm{H}_{\beta}, \mathrm{Na}, \mathrm{O}$, and the electrode elements were observed. The intensities from the emission lines of the electrode elements changed for each electrode, as shown by the spectroscopic measurements in Table II. For most electrodes, the excitation temperatures were in the range of 4000-5000 K, and the relative emission intensities of $\mathrm{O}$ were $10-15 \%$ against a reference intensity of $100 \%$ for $\mathrm{H}_{\alpha}$. For the $\mathrm{Zn}$ electrode, it was difficult to calculate the 


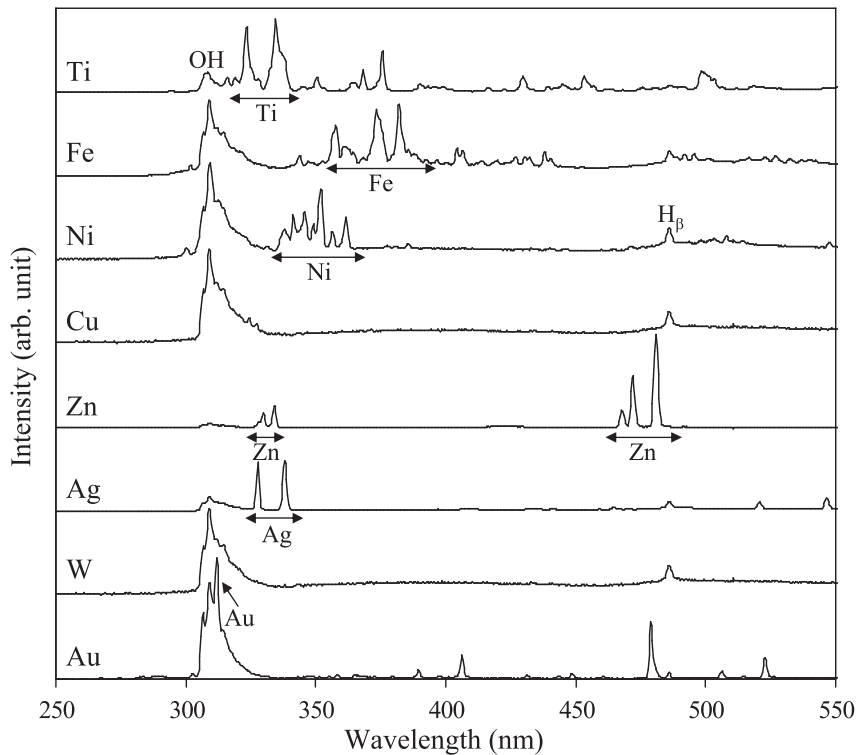

FIG. 7. Spectra of the plasma for each electrode material observed at $0.1-\mathrm{M}$ $\mathrm{NaOH} 140-\mathrm{V}$ conditions.

excitation temperature from the hydrogen lines because of a strong $\mathrm{Zn}$ emission line near the $\mathrm{H}_{\beta}$ line. The emission intensities of $\mathrm{Na}$ and $\mathrm{OH}$ radicals depended on the material, and the emission intensities of $\mathrm{Na}$ and $\mathrm{OH}$ tended to increase with an increase in the emission of ions from the electrode.

In Table II, the excitation temperature $\mathrm{T}_{\mathrm{e}}$ was calculated by evaluating the $\mathrm{H}_{\alpha}$ and $\mathrm{H}_{\beta}$ lines. Additionally, the excitation temperatures were also calculated by using the emission lines of the metallic elements. Figure 8 shows the Boltzmann plots for the $\mathrm{Zn}, \mathrm{Ni}$, and $\mathrm{Au}$ electrodes. We could not estimate the excitation temperatures of other electrode materials because of the lack of data, spectrum overlap, and limited

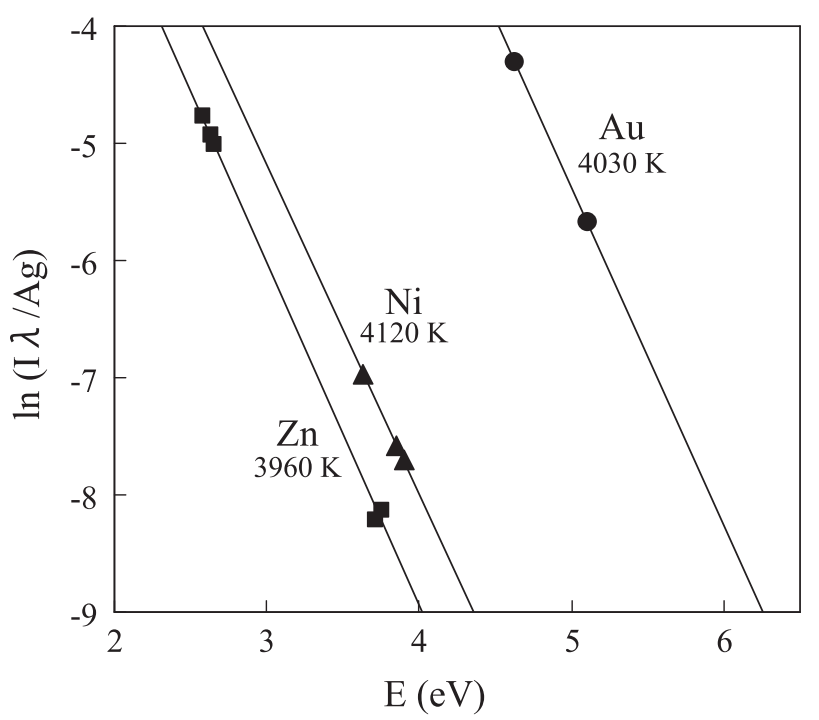

FIG. 8. Boltzmann plots for the measured intensity of the $\mathrm{Zn}, \mathrm{Ni}$, and $\mathrm{Au}$ lines with the excitation temperature obtained by the emission intensities of $\mathrm{Zn}(330,335,468,472$, and $481 \mathrm{~nm})$, Ni $(357,362$, and $386 \mathrm{~nm})$, and $\mathrm{Au}$ (312 and $628 \mathrm{~nm})$.

number of obtained spectra. The excitation temperature at approximately $4000 \mathrm{~K}$ agreed with the temperature obtained from the hydrogen line for the electrode operating in the $0.1 \mathrm{M} \mathrm{NaOH}$ electrolyte at $140 \mathrm{~V}$. Nanoparticles of Ti, Fe, $\mathrm{Ni}, \mathrm{Zn}, \mathrm{Nb}, \mathrm{Mo}, \mathrm{Ag}, \mathrm{Pt}, \mathrm{Au}$, and alloys were generated, as shown in Fig. 9. Particles could not be obtained from $\mathrm{Cu}$ and $\mathrm{W}$, possibly because the $0.1 \mathrm{M} \mathrm{NaOH}$ solution at $140 \mathrm{~V}$ was not suitable for producing $\mathrm{Cu}$ and $\mathrm{W}$ nanoparticles. In a previous study, we synthesized copper nanoparticles by using a sodium citrate solution. ${ }^{23}$

The high voltage with a partial plasma was effective for size control of various materials, as described in Secs. III A

TABLE II. Summary of spectroscopic measurements at each electrode operating in a $0.1 \mathrm{M} \mathrm{NaOH}$ electrolyte solution at $140 \mathrm{~V}$. The excitation temperature $T_{\mathrm{e}}$ was calculated by evaluating the $\mathrm{H}_{\alpha}$ and $\mathrm{H}_{\beta}$ lines. The particle diameter $\left(D_{\mathrm{p}}\right)$ was obtained from SEM and TEM observations.

\begin{tabular}{|c|c|c|c|c|c|c|c|c|}
\hline \multirow[b]{2}{*}{ Electrode } & \multirow[b]{2}{*}{$T_{\mathrm{e}}(\mathrm{K})$} & \multirow[b]{2}{*}{$D_{\mathrm{p}}(\mathrm{nm})$} & \multicolumn{6}{|c|}{ Relative intensity when $\mathrm{H}_{\alpha}=100(\%)$} \\
\hline & & & $\mathrm{H}_{\beta}$ & $\mathrm{O}$ & $\mathrm{Na}$ & $\mathrm{OH}$ & Ion & Line \\
\hline $\mathrm{Ti}$ & 8151 & $<300$ & 17.9 & 11.7 & 442 & 119.4 & 452.3 & Ti $335 \mathrm{~nm}$ \\
\hline $\mathrm{Fe}$ & 4018 & $<500$ & 6.8 & 11.9 & 220 & 60.0 & 45.2 & $\mathrm{Fe} 382 \mathrm{~nm}$ \\
\hline $\mathrm{Ni}$ & 4609 & $<300$ & 8.7 & 10.7 & 279 & 50.2 & 23.4 & $\mathrm{Ni} 352 \mathrm{~nm}$ \\
\hline $\mathrm{Cu}$ & 3562 & $<500$ & 5.3 & 11.1 & 288 & 31.7 & - & - \\
\hline $\mathrm{Zn}$ & - & $<500$ & - & 11.4 & 8598 & 384.7 & 8219.2 & $\mathrm{Zn} 481 \mathrm{~nm}$ \\
\hline $\mathrm{Zr}$ & 4378 & $<1000$ & 8.0 & 11.9 & 1204 & 78.2 & 60.0 & $\mathrm{Zr} 327 \mathrm{~nm}$ \\
\hline $\mathrm{Nb}$ & 4275 & $<1000$ & 7.6 & 11.1 & 354 & 53.5 & - & - \\
\hline Мo & 4168 & - & 7.3 & 10.0 & 523 & 32.1 & - & - \\
\hline $\mathrm{Ag}$ & 4087 & $<300$ & 7.0 & 14.7 & 362 & 16.6 & 50.4 & Ag $328 \mathrm{~nm}$ \\
\hline W & 4156 & - & 7.3 & 10.6 & 349 & 41.3 & - & - \\
\hline $\mathrm{Pt}$ & 4228 & $<10$ & 7.5 & 11.2 & 448 & 56.2 & - & - \\
\hline $\mathrm{Au}$ & 5277 & $<10$ & 10.7 & 14.6 & 361 & 96.6 & 40.9 & Au $312 \mathrm{~nm}$ \\
\hline Brass & 4144 & $<500$ & 7.2 & 13.8 & 271 & 42.6 & 131.8 & $\mathrm{Cu} 324 \mathrm{~nm}$ \\
\hline $\mathrm{Ni}-57 \% \mathrm{Cu}$ & 4664 & $<500$ & 8.9 & 12.3 & 275 & 48.0 & 128.8 & $\mathrm{Cu} 324 \mathrm{~nm}$ \\
\hline $\mathrm{Ni}-34 \% \mathrm{Cu}$ & 4530 & $<500$ & 8.4 & 12.0 & 298 & 43.3 & 73.1 & $\mathrm{Cu} 324 \mathrm{~nm}$ \\
\hline $\mathrm{Ni}-13 \% \mathrm{Cr}$ & 4331 & $<500$ & 7.8 & 11.4 & 268 & 31.3 & 8.2 & $\mathrm{Ni} 352 \mathrm{~nm}$ \\
\hline $\mathrm{Ni}-10 \% \mathrm{Cr}$ & 4428 & $<500$ & 8.1 & 11.3 & 358 & 46.6 & 17.1 & $\mathrm{Ni} 352 \mathrm{~nm}$ \\
\hline SUS304 & 4237 & $<500$ & 7.5 & 10.5 & 230 & 57.0 & 8.7 & $\mathrm{Fe} 382 \mathrm{~nm}$ \\
\hline SUS316L & 4262 & $<500$ & 7.6 & 11.4 & 234 & 45.6 & 20.0 & Ni $352 \mathrm{~nm}$ \\
\hline
\end{tabular}



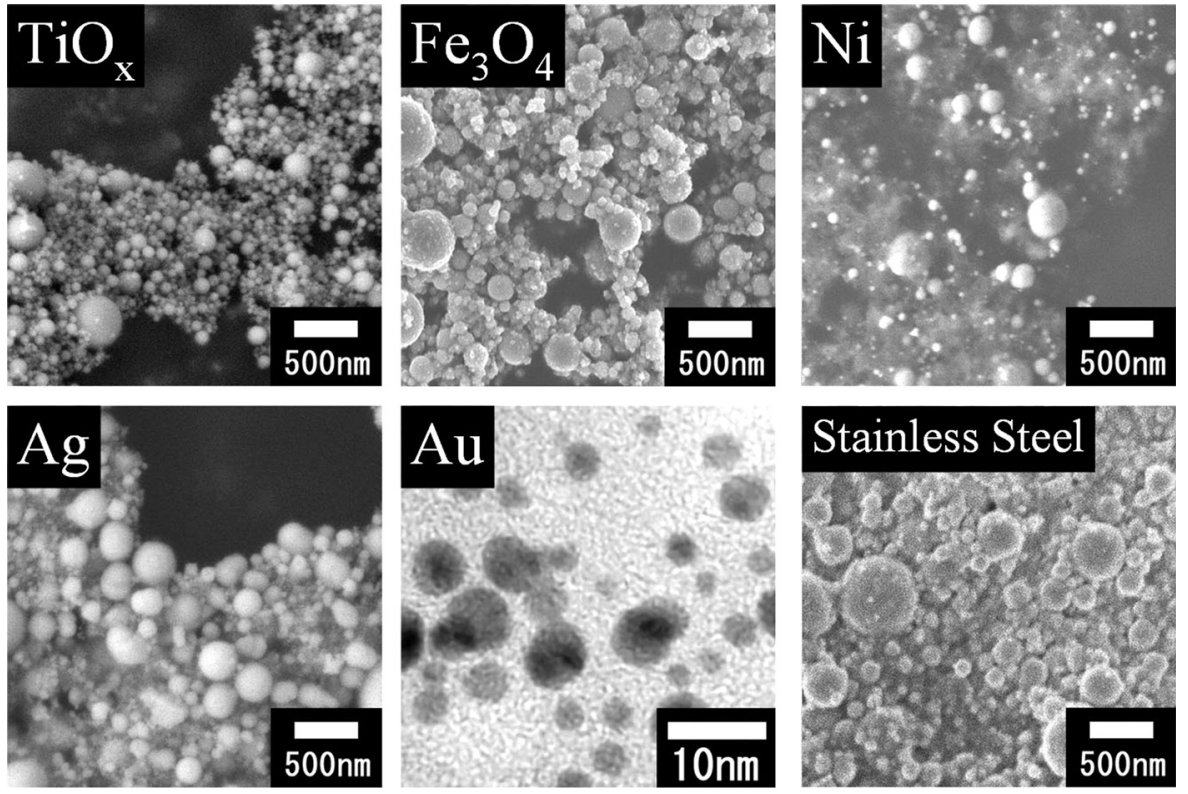

FIG. 9. SEM images of $\mathrm{TiO}_{\mathrm{x}}, \mathrm{Fe}_{3} \mathrm{O}_{4}$, $\mathrm{Ni}, \mathrm{Ag}$, and SUS316 stainless-steel nanoparticles and a TEM image of $\mathrm{Au}$ nanoparticles. and III B. In the case of $\mathrm{Ti}$, the particle size decreased from $197 \mathrm{~nm}$ to $72.5 \mathrm{~nm}$ when the applied voltage increased from 72 to $127 \mathrm{~V}$ in the partial-plasma region. ${ }^{1}$ However, when the applied voltage, current, and excitation temperature were at similar levels, the particle size was different for each material. For example, $\mathrm{Au}$ and $\mathrm{Pt}$ had much smaller particle sizes of less than $10 \mathrm{~nm}$ even though their emission spectra were not much different from those of other materials. Therefore, the formation of nanoparticles was affected not only by the plasma conditions such as the excitation temperature but also by the physical properties of the electrode material, such as melting temperature, density, electrical conductivity, thermal conductivity, vapor pressure, ionization energy, and chemical stability.

\section{CONCLUSION}

In this study, we obtained spectroscopic measurements of solution plasmas using a direct current during nanoparticle synthesis to control the product size and investigate the particles formation. The effects of edge shielding, applied voltage, and electrode material on the plasma were primarily studied. The excitation temperature was measured by applying the Boltzmann plot method assuming LTE. The following conclusions were drawn:

(1) The strong emissions of $\mathrm{H}_{\alpha}, \mathrm{H}_{\beta}, \mathrm{OH}$, and $\mathrm{O}$ were detected via OES. The electrode without edge shielding produced coarse particles with oxidization due to increasing the average temperature of electrode surface to radiate infrared radiation. When the edge was shielded, a fine metallic particles were generated in a partial-plasma region.

(2) When the voltages were varied at different electrolyte concentrations in the partial-plasma region, the excitation temperature increased as the voltage increased: (voltage, concentration, excitation temperature $)=(50 \mathrm{~V}$, $5.0 \mathrm{M}, 3400 \mathrm{~K}),(140 \mathrm{~V}, 0.1 \mathrm{M}, 4500 \mathrm{~K})$, and $(250 \mathrm{~V}$, $0.05 \mathrm{M}, 7000 \mathrm{~K})$. The high applied voltage under partial- plasma region is effective for synthesizing small nanoparticles owing to high excitation temperature.

(3) For most electrodes, the excitation temperatures were the range of 4000-5000 K. Nanoparticles of Ti, Fe, Ni, Zn, $\mathrm{Nb}, \mathrm{Mo}, \mathrm{Ag}, \mathrm{Pt}, \mathrm{Au}$, and alloys were synthesized. The particle size is affected not only by the applied voltage but also by the physical properties of electrode material.

\section{ACKNOWLEDGMENTS}

We would like to thank the "Nanotechnology Platform" Program of the Ministry of Education for allowing us to perform transmission-electron-microscope observations on the nanoparticles produced in our study. We especially wish to thank Mr. Kenji Ohkubo and Mr. Ryo Ota for their great technical assistance and helpful suggestions. The authors would also like to thank Mr. Shigeo Yatsu for many helpful discussions.

\footnotetext{
${ }^{1}$ Y. Nakasugi, G. Saito, T. Yamashita, and T. Akiyama, "Synthesis of nonstoichiometric titanium oxide nanoparticles using discharge in $\mathrm{HCl}$ solution,” J. Appl. Phys. 115, 123303 (2014).

${ }^{2}$ G. Saito, Y. Nakasugi, T. Yamashita, and T. Akiyama, "Solution plasma synthesis of bimetallic nanoparticles," Nanotechnology 25, 135603 (2014). ${ }^{3}$ A. E. E. Putra, S. Nomura, S. Mukasa, and H. Toyota, "Hydrogen production by radio frequency plasma stimulation in methane hydrate at atmospheric pressure,” Int. J. Hydrogen Energy 37, 16000-5 (2012).

${ }^{4}$ G. Saito, S. Hosokai, M. Tsubota, and T. Akiyama, "Ripple formation on a nickel electrode during a glow discharge in a solution," Appl. Phys. Lett. 100, 181601-4 (2012).

5. Gao, A. Wang, Y. Li, Y. Fu, J. Wu, Y. Wang, and Y. Wang, "Synthesis and characterization of superabsorbent composite by using glow discharge electrolysis plasma," Reactive Funct. Polym. 68, 1377-1383 (2008).

${ }^{6}$ T. Maehara, K. Nishiyama, S. Onishi, S. Mukasa, H. Toyota, M. Kuramoto, S. Nomura, and A. Kawashima, "Degradation of methylene blue by radio frequency plasmas in water under ultraviolet irradiation," J. Hazard. Mater. 174, 473-476 (2010).

${ }^{7}$ Y. Liu and X. Jiang, "Plasma-induced degradation of chlorobenzene in aqueous solution," Plasma Chem. Plasma Process 28, 15-24 (2008).

${ }^{8}$ J. Gong, J. Wang, W. Xie, and W. Cai, "Enhanced degradation of aqueous methyl orange by contact glow discharge electrolysis using $\mathrm{Fe}^{2+}$ as catalyst," J. Appl. Electrochem. 38, 1749-1755 (2008).
} 
${ }^{9}$ T. Maehara, I. Miyamoto, K. Kurokawa, Y. Hashimoto, A. Iwamae, M. Kuramoto, H. Yamashita, S. Mukasa, H. Toyota, S. Nomura, and A. Kawashima, "Degradation of methylene blue by rf plasma in water," Plasma Chem. Plasma Process 28, 467-482 (2008).

${ }^{10}$ R. H. Huddlestone and S. L. Leonard, Plasma Diagnostic Techniques (Academic Press, 1965).

${ }^{11} \mathrm{P}$. Bruggeman and C. Leys, "Non-thermal plasmas in and in contact with liquids,” J. Phys. D: Appl. Phys. 42, 053001 (2009).

${ }^{12}$ A. Hickling and M. Ingram, "Glow-discharge electrolysis," J. Electroanal. Chem. 8, 65-81 (1964).

${ }^{13}$ G. Saito, Y. Nakasugi, and T. Akiyama, "High-speed camera observation of solution plasma during nanoparticles formation," Appl. Phys. Lett. 104, 083104 (2014).

${ }^{14}$ K. Azumi, T. Mizuno, T. Akimoto, and T. Ohmori, "Light emission from Pt during high-voltage cathodic polarization," J. Electrochem. Soc. 146, 3374 (1999).

${ }^{15}$ K. Azumi, A. Kanada, M. Kawaguchi, and M. Seo, "Formation of microparticles from titanium and silicon electrodes using high-voltage discharge in electrolyte solution,” J. Surf. Finish. Soc. Jpn. 56(12), 938-941 (2005).

${ }^{16}$ G. Saito, S. Hosokai, M. Tsubota, and T. Akiyama, "Nickel nanoparticles formation from solution plasma using edge-shielded electrode," Plasma Chem. Plasma Process. 31, 719-728 (2011).

${ }^{17}$ Y. Hattori, S. Mukasa, H. Toyota, H. Yamashita, and S. Nomura, "Improvement in preventing metal contamination from an electrode used for generating microwave plasma in liquid," Surf. Coat. Technol. 206, 2140-2145 (2012).

${ }^{18}$ Y. Toriyabe, S. Watanabe, S. Yatsu, T. Shibayama, and T. Mizuno, "Controlled formation of metallic nanoballs during plasma electrolysis," Appl. Phys. Lett. 91, 041501-3 (2007).

${ }^{19}$ G. Saito, S. Hosokai, M. Tsubota, and T. Akiyama, "Surface morphology of a glow discharge electrode in a solution," J. Appl. Phys. 112, 013306-9 (2012).

${ }^{20}$ S. Nomura, S. Mukasa, H. Toyota, H. Miyake, H. Yamashita, T. Maehara, A. Kawashima, and F. Abe, "Characteristics of in-liquid plasma in water under higher pressure than atmospheric pressure," Plasma Sources Sci. Technol. 20, 034012 (2011).

${ }^{21}$ Y. Hattori, S. Mukasa, H. Toyota, T. Inoue, and S. Nomura, "Continuous synthesis of magnesium-hydroxide, zinc-oxide, and silver nanoparticles by microwave plasma in water," Mater. Chem. Phys. 131, 425-430 (2011).

${ }^{22}$ G. Saito, S. Hosokai, T. Akiyama, S. Yoshida, S. Yatsu, and S. Watanabe, "Size-controlled Ni nanoparticles formation by solution glow discharge," J. Phys. Soc. Jpn. 79, 083501 (2010).

${ }^{23}$ G. Saito, S. Hosokai, M. Tsubota, and T. Akiyama, "Synthesis of copper/ copper oxide nanoparticles by solution plasma," J. Appl. Phys. 110, 023302 (2011).

${ }^{24}$ T. Maehara, S. Honda, C. Inokuchi, M. Kuramoto, S. Mukasa, H. Toyota, S. Nomura, and A. Kawashima, "Influence of conductivity on the generation of a radio frequency plasma surrounded by bubbles in water," Plasma Sources Sci. Technol. 20, 034016 (2011).

${ }^{25}$ P. Bruggeman, D. Schram, M. Á. González, R. Rego, M. G. Kong, and C. Leys, "Characterization of a direct dc-excited discharge in water by optical emission spectroscopy," Plasma Sources Sci. Technol. 18, 025017 (2009).

${ }^{26}$ S. Z. Mortazavi, P. Parvin, A. Reyhani, A. N. Golikand, and S. Mirershadi, "Effect of laser wavelength at IR $(1064 \mathrm{~nm})$ and UV $(193 \mathrm{~nm})$ on the structural formation of palladium nanoparticles in deionized water," J. Phys. Chem. C 115, 5049-5057 (2011).

${ }^{27}$ K. Kobayashi, Y. Tomita, and M. Sanmyo, "Electrochemical generation of hot plasma by pulsed discharge in an electrolyte," J. Phys. Chem. B 104, 6318-6326 (2000).

${ }^{28}$ K. R. Stalder and J. Woloszko, "Some physics and chemistry of electrosurgical plasma discharges," Contrib. Plasma Phys. 47, 64-71 (2007).

${ }^{29}$ S. Mukasa, S. Nomura, H. Toyota, T. Maehara, F. Abe, and A. Kawashima, "Temperature distributions of radio-frequency plasma in water by spectroscopic analysis," J. Appl. Phys. 106, 113302-6 (2009).

${ }^{30}$ S. Nomura, H. Toyota, S. Mukasa, Y. Takahashi, T. Maehara, A. Kawashima, and H. Yamashita, "Discharge characteristics of microwave and high-frequency in-liquid plasma in water," Appl. Phys. Express 1, 046002 (2008). 